\title{
\#26
}

\section{LA FAMILIA COCONETA \\ Y EL ARMARIO DE \\ ELENA: \\ DOS MICROPIEZAS \\ DESCONOCIDAS DE \\ MAX AUB}

Esther Lázaro Sanz

ICTT, Avignon Université / GEXEL-CEDID,

Universitat Autònoma de Barcelona

https://orcid.org/0000-0002-7250-0237

Artículo || Invitado | Publicado: 01/2022

DOI 10.1344/452f.2022.26.7

esther.lazaro@uab.cat

Ilustración || @ Nacho Gómez Sales - Todos los derechos reservados

Texto || (c) Esther Lázaro Sanz - Licencia: Atribución-NoComercial-SinDerivadas 4.0 Internacional de Creative Commons

\section{(c) $(1) \Theta(\Theta)$}




\section{$452^{\circ} \mathrm{F}$}

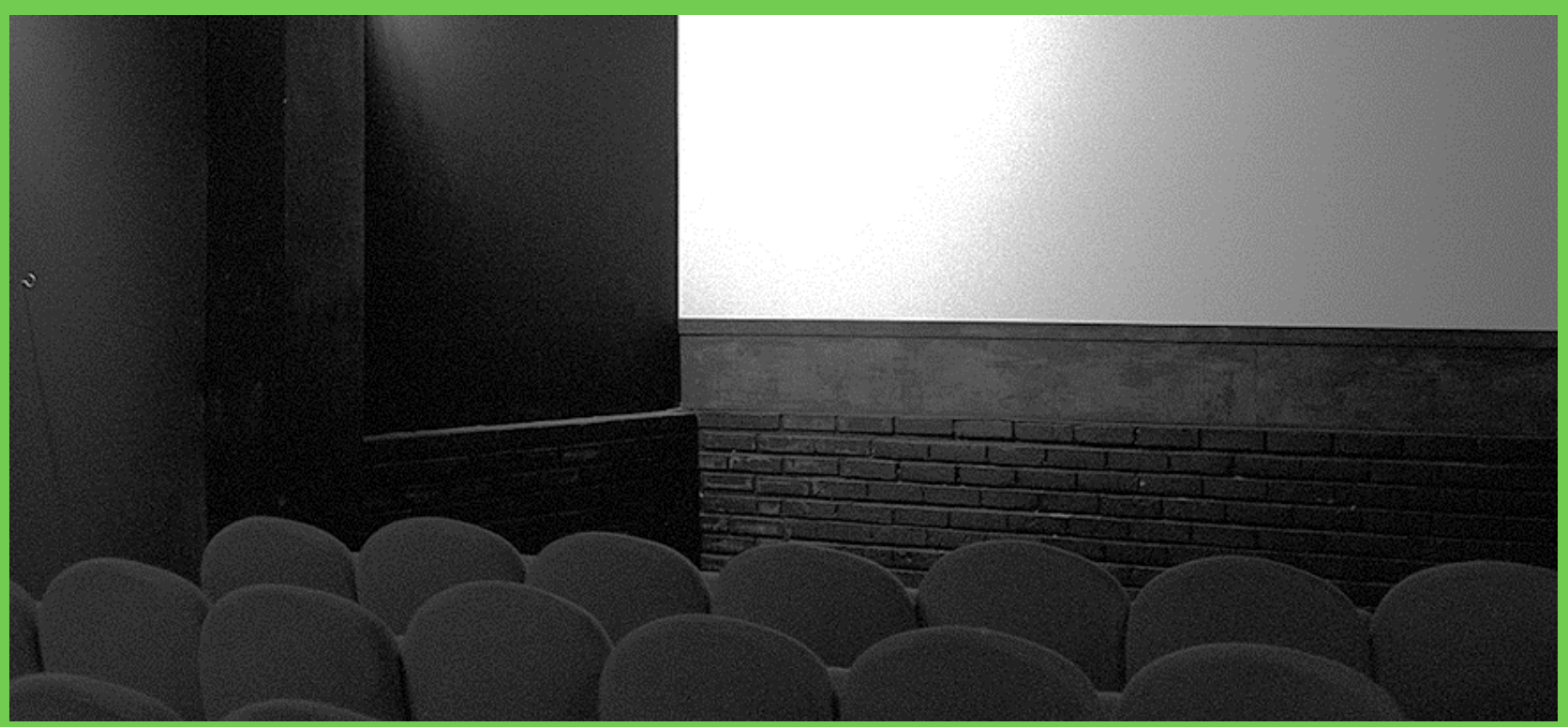

Resumen || A pesar de cultivar todos los géneros, y aunque se le conozca más como narrador, el teatro tuvo siempre un lugar preferente para Max Aub, emblemático autor del exilio republicano de 1939. Así lo atestiguan no solo su medio centenar de obras dramáticas publicadas en vida, sino también sus cerca de treinta piezas inéditas. Entre unas y otras, se encuentran además piezas teatrales breves insertas en obras de otros géneros que han pasado desapercibidas por la crítica, u obras que se publicaron de manera póstuma en ediciones de coleccionista. Es el caso de las dos micropiezas a las que está dedicado este trabajo, La familia Coconeta y El armario de Elena, donde Aub propone un juego autoficcional en el que convierte tanto a su familia como a él mismo en personajes de obras breves en la estética del absurdo y cuya finalidad es puramente lúdica. En estas páginas analizamos el contenido de ambas piezas, tratamos de descifrar sus claves y subrayar su intertextualidad y su transculturalidad, a su vez indagamos en el proceso de su escritura a partir de los materiales textuales localizados en varios archivos internacionales.

\section{Palabras clave || Max Aub | Microteatro | Autoficción | Teatro del absurdo | Exilio republicano}

Abstract || Max Aub was an emblematic writer of the Spanish Republican exile of 1939; he cultivated all literary genres, and is better known as his work as novelist, however, he also privileged theatre among his literary production. This is proved not only by his fifty dramatic works published in life, but also by his almost thirty unpublished pieces. In addition, there are short plays inserted in works of other genres that have gone unnoticed by critics, or plays that were published posthumously in collector's editions. This is the case of the two micro-plays studied in this paper: La Familia Coconeta and El armario de Elena. In such plays, framed within the aesthetics of the absurd, Aub proposes an auto-fictional game in which he turns his family and himself into characters whose purpose is purely playful. In this article, we analyze the content of both plays, we try to find out their distinctive keys and we aim at underlining their intertextuality and transculturality, as well as look into his writing process through textual materials located in different international archives.

\section{Keywords || Max Aub | Micro-plays | Auto-fiction | Theatre of the Absurd | Spanish Republican exile}

Resum || Malgrat conrear tots els gèneres, i encara que se'l conegui més com a narrador, el teatre va tenir sempre un Iloc preferent per a Max Aub, emblemàtic autor de l'exili republicà de 1939. Així ho testifiquen no sols el seu mig centenar d'obres dramàtiques publicades en vida, sinó també les seves prop de trenta peces inèdites. Entre les unes i les altres, es troben també peces teatrals breus inserides en obres d'altres gèneres que han passat desapercebudes per la crítica, o obres que es van publicar de manera pòstuma en edicions de col·leccionista. És el cas de les dues micropeces a les quals està dedicat aquest treball, La familia Coconeta i El armario de Elena, on Aub proposa un joc autoficcional en el qual converteix tant a la seva família com a ell mateix en personatges d'obres breus en l'estètica de l'absurd i la finalitat de les quals és purament lúdica. En aquestes pàgines analitzem el contingut de totes dues peces, tractem de desxifrar les seves claus i subratllar la seva intertextualitat i la seva transculturalitat, així com indaguem en el procés de la seva escriptura a partir dels materials textuals localitzats en diversos arxius internacionals.

Paraules clau II Max Aub | Microteatre | Autoficció | Teatre de l'absurd | Exili republicà 


\section{Introducción}

Aunque el nombre de Max Aub, emblemático autor del exilio republicano de 1939, esté más asociado a su ciclo novelístico El laberinto mágico, dedicado a la guerra civil española, o a otras obras narrativas como sus microrrelatos Crímenes ejemplares, el propio autor afirmaba que había nacido «para escribir teatro» (Kemp, 1972: 380), labor que no abandonó nunca, a pesar de su escasa fortuna en las tablas, que él atribuía, justamente, a la guerra y al exilio (Aub, 1974a: 522n.). Esa vocación teatral de Aub queda atestiguada en su medio centenar de obras dramáticas publicadas en vida, además de las cerca de treinta que permanecen inéditas (Lázaro Sanz, 2019).

Sin embargo, entre las publicadas, se cuentan algunas que han sido escasamente atendidas por la crítica por encontrarse insertas en obras de otros géneros y haber pasado desapercibidas como piezas teatrales. Influye también que sean piezas muy breves o brevísimas, cosa que nos permite hablar de ellas como de piezas microteatrales, si seguimos la tipología propuesta por Gómez Vázquez (2017: 120) para determinar qué englobaría esta etiqueta microtextual dramática. Entre las micropiezas inadvertidas del autor encontramos Una criada, Zarzuela, Monólogo con Federico y con Miguel, Paso del señor Director General de Seguridad y María ${ }^{1}$. A este cómputo podría añadírsele parte del teatro de circunstancias escrito durante la Guerra Civil en pro del bando republicano, como Juan ríe, Juan llora, Las dos hermanas, Por Teruel o ¿Qué has hecho hoy para ganar la guerra?2, así como su microteatro inédito, compuesto por La mañana siguiente, Crimen, México, Monólogo de un actor, En un campo de concentración, en octubre de 1943, Monólogo de un comunista y [María D.] (Lázaro, 2021). Las dos piezas que aquí nos ocupan, La familia Coconeta y El armario de Elena, tienen la particularidad de haber sido publicadas póstumamente junto con otros materiales de difícil acceso, como se verá a continuación.

En 2013, el Centro de Arte Moderno de Madrid, como homenaje al ciento décimo aniversario del nacimiento de Aub, publicó una pequeña virguería bibliográfica que tituló Cartas a mi hija Elena, cuya edición estuvo a cargo de Claudio Pérez Míguez. Dicho objeto literario consiste en un estuche entelado que contiene reproducciones facsímiles de diecinueve postales, dos dedicatorias en libros que el autor regaló a su hija mediana, cinco cartas, un grabado dedicado, el manuscrito del poema «Te acuerdas, Elena...», su versión mecanuscrita y otra versión a limpio en una carta, tres fotografías, dos obras breves de teatro y una carpeta con la transcripción de todos estos materiales y una nota del editor ${ }^{3}$.

Estos documentos, inéditos hasta la publicación de este libro-estuche, fueron proporcionados a Pérez Míguez por Elena Aub Barjau (1931-2020), hija mediana del escritor. Sin embargo, el libro es de tan difícil acceso, ya que la tirada fue de cien ejemplares firmados y numerados por el editor, y su precio de venta es digno de un objeto artístico -motivo por el cual, hasta la fecha, no se encuentra en ninguna biblioteca del Estado, ni siquiera en la Biblioteca Nacional de España-, que las dos obras dramáticas que en él aparecen, La familia Coconeta y El armario de Elena, siguen siendo 
prácticamente desconocidas y no han sido atendidas por la crítica especializada ni se las incluye en las bibliografías teatrales del autor.

Por ello, consideramos que merece la pena ofrecer un análisis minucioso de estos textos, ya que nada se ha escrito sobre ellos, más allá de las breves palabras que le dedica el editor en su nota a uno de ellos: «La familia Coconeta de una de las obras de teatro se corresponde con su familia: Max y Perpetua —Peua-, y sus tres hijas Mimin [sic], Elena y Carmen» (Pérez Míguez, 2013). Para este trabajo, además, se ha recurrido a la búsqueda en los fondos del autor en varios archivos internacionales para determinar el proceso de escritura de estas micropiezas y tratar de aportar la mayor información posible acerca de los materiales textuales relativos a ellas, además de las reproducciones facsimilares contenidas en Cartas a mi hija Elena.

\section{La familia Coconeta (1947)}

\subsection{Descripción de los materiales textuales}

El manuscrito de La familia Coconeta se encuentra en el fondo maxaubiano del Archivo de la Diputació de València (en adelante, ADV. C.8-1), custodiado en la Fundación del autor. Está escrito en tinta azul y ocupa seis páginas de la libreta en la que se encuentra, de la 91 a la 96. No hay apenas diferencias, en cuanto al contenido o a la forma, entre el manuscrito y la última versión mecanuscrita, salvo dos detalles. El primero es la inclusión en el mecanuscrito de la palabra «Personajes» antes del listado de los ídems, detalle que no aparece en el manuscrito, donde la lista no va encabezada por el sustantivo aclaratorio. Y el segundo detalle es la única corrección que aparece en el manuscrito y que, por tanto, queda ya subsanada en las versiones mecanuscritas, y que enmienda el nombre de uno de los personajes, a quien Aub bautiza primero como «María Luisa» y luego, tras tacharlo, anota encima «Mimín». Como otros datos de interés que nos aporta este documento destaca la marca característica con la que Aub señalaba que un texto había sido pasado a limpio, es decir, mecanografiado: una tachadura en diagonal (a veces eran dos, formando una cruz) desde el ángulo superior derecho hasta el inferior izquierdo del folio. En este caso, la marca aparece en tinta verde. Y, como curiosidad, la página en la que inicia la micropieza había sido utilizada con anterioridad para anotar dos versos, que aparecen muy tachados en la parte superior del folio, pero de los que se alcanza a leer «Todo [ilegible] por el mundo / mejor tú, mi España».

La versión definitiva ${ }^{4}$ se encuentra en el fondo de Aub del Archivo Histórico del Colegio de México (AHC. C.17.s/V.D.19). Dicho documento se compone de dos copias iguales mecanuscritas de la pieza, con cinco folios cada una. En una de ellas encontramos varias correcciones manuscritas que consisten en la supresión (con tachaduras) del apellido de uno de los personajes y de un pero; de la corrección de una mayúscula inicial que se mecanografió minúscula; de una marca para unir una letra que había quedado espaciada al resto de la palabra; y de dos cambios de los que se arrepintió, ya que, en el primero, escribe a mano encima de la palabra 
mecanografiada chupa otro verbo que luego tacha, quedando ilegible, y escribe, abajo, de nuevo, chupa, y lo mismo ocurre las dos veces que aparece la palabra cadáver, que tacha para cambiarla por espectro, que luego borra ligeramente y escribe otra vez cadáver, como estaba desde un principio en el mecanuscrito (y en el manuscrito).

Sin embargo, el mecanuscrito reproducido facsimilarmente en Cartas a mi hija Elena no se corresponde con ninguna de las dos copias que encontramos en el archivo mexicano, sino con lo que sería una transcripción anterior del manuscrito, ya que mantiene el contenido íntegro de este, sin tachaduras ni correcciones. El cotejo de los tres mecanuscritos nos revela que el facsimilar tiene una distribución ligeramente distinta en cuanto a las alineaciones de las didascalias y del texto, por ejemplo, así como alguna errata que no se mantiene en los mecanuscritos del archivo mexicano, hechos que indican que no se trata del mismo documento. A pesar de ello, vamos a fijarnos en el mecanuscrito descrito anteriormente, corregido, por considerarlo la última versión acorde con los deseos del autor, como marca la tradición de la crítica textual (Blecua, 2012: 18; LluchPrats, 2009).

El título aparece en mayúsculas, centrado y subrayado. La lista de personajes está alineada a la izquierda, pero entre el título y el dramatis personae encontramos, alineado hacia la derecha, aunque no completamente en el margen, «Los espectros», también subrayado. Las didascalias de personaje aparecen centradas, en la línea superior a cada réplica, y subrayadas; las acotaciones, entre paréntesis. El inicio de cada intervención aparece tabulado, y las acotaciones que no están insertas en las réplicas se inician a partir de la mitad de la página.

\subsection{Contenido y análisis de la pieza}

La familia Coconeta es, sin lugar a dudas, una de las piezas más singulares del teatro de Aub. Además, se trata de una pieza en clave, es decir, que sus personajes se corresponden con personas reales, en este caso del entorno familiar y cotidiano del autor. Se desmarca de toda la producción dramática aubiana, fundamentalmente realista -aunque con concesiones-, para seguir una estética de teatro del absurdo que no se conocía en el autor hasta ahora. El crítico Winston Manrique Sabogal —el único que, hasta el momento, ha comentado esta pieza en la reseña que le dedicó al libro-estuche desde las páginas culturales de El País- la define como «una breve pieza surrealista que no parece ir a ningún lado escrita para divertimento de sus mujeres» (Manrique Sabogal, 2013). Las afirmaciones que pueden hacerse sobre esta obra son relativas, por lo que el análisis se basará en hipótesis más o menos justificadas que podrían ser acertadas (o podrían también no serlo).

El inicio didascálico de la pieza entraña alguna incertidumbre. Si empezamos por el título, Coconeta podría ser una deformación cariñosa de cócono, vocablo mexicano para pavo. Si, en cambio, lo leemos como un galicismo, podría ser una deformación y castellanización de cocon, palabra francesa para capullo. Ambas interpretaciones podrían tener su sentido: en 
la interpretación afrancesada, el capullo, es decir, el envoltorio que construye el gusano de seda para encerrarse en él y transformarse en crisálida, podría relacionarse con la familia, con el lugar en el que uno está seguro, protegido, antes de «salir al mundo». Pero también tendría sentido considerar que Coconeta podría entenderse como Pavita, dentro del contexto lúdico-jocoso que plantea la pieza, e iría también más acorde con el ambiente mexicano de la misma.

Como se apuntaba en la descripción del documento, ese «Los espectros», que encontramos entre el título y la lista de personajes, no queda claro si ocupa el lugar de un subtítulo o bien es un personaje colectivo descolocado, ya que en la pieza intervienen varios espectros, con sus respectivos nombres, pero que no aparecen, en cambio, en el dramatis personae. Ese dramatis personae nos da la clave de la obra porque los personajes son: «Papá Coconet, Mamá Coconeta, Mimín Coconet, Elena Coconeta» y «Carmen Coconetita». Se trata, evidentemente, de Max Aub y su propia familia. Por si hubiera alguna duda, en el manuscrito, como se ha indicado, cambió el nombre de María Luisa por el de Mimín, apodo cariñoso con el que llamaban a la hija mayor.

Max Aub y Perpetua Barjau se casaron el 3 de octubre de 1926 —después de ocho años de noviazgo, iniciado el 31 de octubre de 1918 (Aub, 2003: 416) — en la iglesia de San Andrés de Valencia (Aub, 1998: 106n.),

\begin{abstract}
tempranito porque tomamos el tren para Madrid. A la hora de comer, nos encontramos en el carro-comedor con Pedro Salinas. Como siempre, fui a dar al hotel Gran Vía - que todavía resiste- y dimos, al llegar, en el hall, naturalmente por casualidad, con Enrique Díez-Canedo. Estuvimos en Madrid como tres semanas. Luego fuimos a Burgos [...], donde una madrugada tuve que salir porque mi mujer tuvo antojo de comerse un panecillo con chorizo. Luego Vitoria [...]. Luego San Sebastián [...]. Fuimos a Bilbao [...] donde íbamos a la tertulia de Mourlane Michelena y con Manuel de la Sota y Somonte, que luego fue alcalde republicano de Bilbao. Santander [...], Oviedo [...], Gijón y la tertulia de Gerardo Diego [...]. Bajamos a León, fuimos a La Coruña, donde tenía tantos amigos reunidos alrededor de Alfar y de su rubicundo y espléndido director, Julio J. Casal. Santiago, Vigo. Una noche en Astoria y una semana en Zamora [...]. Valladolid, Madrid otra vez, un par de días. Calatayud, Zaragoza para volver a Valencia el 22 de diciembre. Inútil decirle que además del viaje de bodas era viaje de negocios (Aub, 1986: 130-131 o AFMA. C.11-39/105).
\end{abstract}

Seis meses después de la boda, el 8 de abril de 1927, nació María Luisa, su primera hija. Elena, la segunda, llegó al mundo el 18 de septiembre de 1931, y Carmen, la menor, lo hizo pocos días después de estallar la Guerra Civil, el 30 de julio de 1936 (Retorno..., 2017: 139). Las tres nacieron en Valencia, igual que su madre. Durante los convulsos años de la guerra, a raíz del nombramiento de Aub como agregado cultural de la Embajada de España en París, Perpetua y sus hijas se trasladan a la capital francesa en marzo de 1937 (Malgat, 2013: 81), y permanecerán allí hasta 1940, momento en el que -ante el arresto de Aub y el inicio de su periplo concentracionario- regresan a Valencia. La familia no volverá a reunirse hasta al cabo de varios años, en septiembre de 1946, establecido ya el autor en México (Aznar Soler, 1998: 17).

Hasta donde sabemos, esta es la única ocasión en la que Aub convierte a sus hijas en personajes de una obra teatral, a excepción de Elena, como 
veremos en El armario de Elena. No es el caso, en cambio, de Peua (diminutivo con el que se referían a Perpetua), quien volverá a aparecer como personaje en una de sus últimas piezas, el Paso del señor Director General de Seguridad ${ }^{6}$, aunque en esta ya como «P.» (Aub, 2021: 575) y no bajo ningún sobrenombre como en la que nos ocupa.

La acotación inicial de La familia Coconeta nos indica que la acción tiene lugar en «el comedor de la familia Coconet. Cierto desorden. Está amaneciendo» 7 . En esta acotación apreciamos algo que también se ve en el listado de personajes, que son las dos variantes del nombre de la familia, Coconeta o Coconet, que parece usar indistintamente. Este comedor de la familia podría muy bien ser el del piso tercero de Euclides 5, vivienda de los Aub Barjau en Ciudad de México. En esa misma acotación, Aub indica la entrada en escena de uno de los personajes que no aparece en el dramatis personae: «el espectro de Rubén».

En el mecanuscrito, como se ha señalado anteriormente, el apellido de Rubén aparece tachado, pero en el manuscrito leemos claramente que el nombre del espectro era Rubén Rojo. Es muy probable que se trate del actor español nacionalizado mexicano Rubén Rojo Pinto (1922-1993), quien trabajó mucho en la época de oro del cine mexicano, donde seguramente coincidió con Aub. Era hijo, además, de la escritora, periodista, dramaturga, divulgadora y feminista canaria Mercedes Pinto (1883-1976), quien, a pesar de haberse exiliado de España durante la dictadura de Primo de Rivera para no acatar la orden de destierro a la que le condenó el dictador en 1923, apoyó fuertemente la causa republicana desde Cuba durante la Guerra Civil y, a partir de 1943, se trasladó a México con sus hijos ${ }^{8}$. A pesar de que no aparezca ninguna mención sobre Pinto o su descendencia (tres de ellos, actores -Rubén, Gustavo y Pituka de Foronda-) en los diarios del autor, resulta evidente que, al menos a los intérpretes, sí les conocía: los tres hermanos actuaron en la compañía El Bú, que dirigió Aub en México en 1944 (Diago, 2015: 178). Pituka, además, como actriz profesional con trayectoria (Díaz Bethencourt, 1995), estuvo en el elenco principal que estrenó ese mismo año La vida conyugal (Paulino Ayuso, 2010: 51). En el caso de Rubén, aunque no coincidió con Aub en ninguna película durante los años en que ambos trabajaban en la industria cinematográfica mexicana, sí protagonizó algunos films de Buñuel como El gran calavera (1949) o La hija del engaño (1951). En cuanto a su hermano Gustavo, actor también en El gran calavera -y presente también en esta micropieza, como se verá a continuación-, él sí trabajó con Aub en Amok (1944), dirigida por Antonio Momplet, en la que nuestro autor colaboró como dialoguista, y en Barrio de pasiones (1948), de Adolfo Fernández Bustamante, donde Aub trabajó como adaptador.

El «espectro de Rubén», pues, entra a escena y pronuncia unas fórmulas mágicas — «Jamalajá, jamalajá [...]. Jamalajá Coconeta»-mientras «echa unos polvos» y «se oye una música lejana». A continuación, una «voz fuera», tal vez de un vendedor ambulante, tan habituales en México, grita: «Hay naranjas! ¡Hay naranjas!». Y aparece en escena otro personaje, «Espectro de Gustavo», a quien atribuimos la identidad de Gustavo Rojo (1923-2017). Declama unas frases exclamativas que pueden sonar tanto a (parodia de) obra clásica, como a guion cinematográfico de esas películas 
comerciales del cine mexicano que Aub consideraba «horrendas» aunque tuviera que escribirlas (Aub, 1998: 146): «¡Oh, sol! ¡Oh, mañana recién nacida! ¡Oh, noche! ¡La sangre no será nada! ¡Mueran! ¡Mueran!». A esa intervención le sigue la de la voz exterior, que repite sus gritos, y luego la de Rubén, que vuelve a gritar su «jJamalajá!».

Con eso termina la breve introducción, ya que la acotación nos indica que «desaparecen los espectros porque entra Elena», quien, «cruzando la escena», dice: «Paco, Luis, Fede, Pedro, José, Rubén, Pepito, Vicente, Max, Santiago, Jaime, Horacio, Bigotito, perillita, calzoncillo», y sale. Carmen entra tras Elena mientras solfea: «Do, re, mi, fa, sol, la, do, mi, si. Elena quiere a Santiago, Elena quiere a Jaime, Elena quiere a Vicente. Tengo 500 sellos, tengo 1452 sellos. Tengo 20 para chiclets [sic]». Y vuelve a oírse la voz anunciando que «¡Hay naranjas, hay naranjas!», antes de que la acotación informe de la salida de Carmen y la entrada de Mimín, quien dice: «Tengo que escribir pero no escribo porque si escribiera ya no tendría que escribir. Tengo que estudiar pero no estudio porque si estudiara ya no tendría que estudiar».

A ella la sigue Mamá Coconeta: «Mimín me ha cogido mis ligas, Elena me ha cogido mi bata, Carmen me ha cogido mis zapatillas. ¿Por qué Henry Fonda le da un beso a Eleanor Parker? ¿Cuándo llueve? ¿Cuando hace sol ? $^{9}$. Tras la salida de Mamá Coconeta, entra Papá Coconet: «Salkind me debe tres mil pesos, que es como si no me debiera nada. Luis tiene que matar a José Luis. Pero si está en Chicago y el otro en San Luis. ¿Cómo Luis puede matar a José Luis en San Luis? ¿Una disolvencia? ¡Una disolvencia!», y «sale contentísimo» mientras repite su ocurrencia: « Una disolvencia!», que es un término cinematográfico para referirse a, «en una proyección, transición gradual de un plano a otro, que consiste en la mezcla de los últimos momentos de una secuencia con los primeros de otra, para indicar así una elipsis de tiempo», según la definición del Diccionario de la Real Academia Española (2021) o, según la del propio Aub en su Diccionario cinematográfico inédito, «paso de una escena a otra por medio de la superposición de las últimas imágenes de una toma sobre las primeras de la siguiente» (AFMA. C.32-16, p. 45).

Todos los personajes principales de la familia, pues, se han ido sucediendo en escena uno detrás del otro, aportando una intervención a la micropieza que será la que, como se señalará más adelante, les definirá. Después de la entrada y salida sucesiva de cada uno de ellos, Aub acota que «vuelven a salir todos", a pesar de que se refiere a entrar, porque la escena ha quedado vacía unos segundos, tras la marcha de Papá Coconet, «y se sientan a la mesa. Ya es de día. Se ponen a comer. Les sirven los espectros de Rubén y Gustavo». En la mesa, sigue la tónica de las intervenciones individuales:

Mimín ${ }^{10}:$ Tengo que ir a la Universidad para comprarme un sujetador.

Elena: Luis, Pepe, Gustavo, Juan, Pedro, Albacete Manzanero, Santiago, Max, Horacio.

Carmen: La del 102, la del 108, la del 110, la del 801, la del 802. ¡Yo me quiero columpiar!

Mamá: Come, come, come, come. Toma tus pastillas. ¿Por qué besa Henry Fonda a Irene Dunn? 
En este momento se da la primera interacción entre ellos, ya que Carmen responde a la pregunta de su madre: «No es Irene Dunn, mamá». Pero la intervención del Papá retoma el mecanismo de individualidad de las réplicas: « ¿Y si en vez de Luis fuese Pepe Luis quien matara a Luis en Nueva Orleans?».

Esta escena en la mesa se interrumpe por la llegada de la comida: «Los espectros de Rubén y Gustavo traen el cadáver de Pin en una bandeja. Lo dejan en medio de la mesa y la familia Coconet empieza a comérselo». Y, mientras comen, sí que aparece definitivamente la interacción entre ellos:

Carmen: ¡Yo no quiero los sesos, no me gustan!

Elena: Yo no quiero pierna.

Mimín: Yo no quiero el cuello.

Papá: ¡A comer y a callar!

Mamá: Yo quiero la barca.

(El papá abre en dos el cadáver de Pin y salen palomas. Cada uno toma una paloma y la chupa).

Y, de nuevo, la incomunicación:

Carmen: 801, 802, 803.

Elena: Rafael, Carlos, Vicente, Pepe.

Mimín: Yo soy tonta.

Papá: No hay duda: Panchito tiene que matar a Don Pancho.

Mamá: ¿Por qué besa Robert Taylor a Henry Fonda?

Y rompe la falsa conversación la aparición de un nuevo personaje, el cual condicionará el destino de la familia: «el espectro de Paquito Bosch». Al verle, Mimín primero y Elena después exclaman su nombre, «iPaquito!», y mueren. Carmen, en cambio, le pregunta al espectro:

Carmen: ¿De qué color llevas los calzoncillos?

Paquito: Verdes y lilas.

Carmen: ¡A verlos!

(Paquito se quita los pantalones y enseña sus calzoncillos lilas y verdes).

La Mamá se suma a la conversación — « ¿No tiene más que ese par?»-, pero no le da tiempo al espectro a responder, ya que «el cadáver de Pin se anima y se [lo] lleva». Carmen comenta el gesto a su madre - "iSe van! ¡Se van a besar en el elevador!»-, pero esta la advierte de un peligro inminente: «¡Cuidado! ¡Te va a atropellar el aparador!». Efectivamente, «el aparador atropella a Carmen", que parece correr la misma suerte que sus hermanas. El padre, sin inmutarse, le dice a la madre: «Estoy cansado, vámonos a dormir». La acotación indica que «ya es de noche» y que ambos salen. Vuelve a oírse la voz que proviene de fuera con su doble grito de « ¡Hay naranjas!». Otra acotación informa de que los espectros de Rubén y Gustavo, que han debido permanecer en escena desde que aparecieron con el cadáver para el almuerzo/cena, "se felicitan y se suicidan", a pesar de que, si son espectros, es porque ya estaban muertos. De nuevo la voz exterior repite su grito y "Carmen se levanta» y, antes de que caiga el telón, dice: «Me falta la bandera de Siberia y el escudo de Portugal». 
Con esta descripción del contenido de la pieza se puede apreciar bastante el carácter absurdo de la misma. Los diálogos sin sentido y repetitivos, las situaciones ilógicas, la manifiesta falta de comunicación entre los personajes, la incoherencia, la atmósfera onírica, lo disparatado... todo son rasgos característicos del teatro del absurdo, surgido a raíz de la crisis existencial posterior a la segunda guerra mundial y cuyos principales exponente son Eugène lonesco y Samuel Beckett, con obras tan célebres en el género como La cantante calva (1950) o Esperando a Godot (1953), a pesar de que la nómina de dramaturgos que ha practicado este género cómico-dramático es extensa. Martin Esslin, quien acuñó el término «teatro del absurdo» en su ensayo dedicado al mismo (1966), incluyó en ese trabajo, además de a los dos autores ya citados, a Arthur Adamov y a Jean Genet, y dedicó un capítulo a otros dramaturgos que considera "seguidores» de los cuatro autores principales del absurdo, aunque presenten tendencias paralelas, como serían Harold Pinter, Boris Vian, Dino Buzzati o Edward Albee, entre otros.

Pero podemos encontrar ejemplos también en el mismo teatro del exilio republicano, como sería el caso de José Ricardo Morales, _precursor de la estética del absurdo con su El embustero en su enredo, estrenado por Margarita Xirgu en $1945^{11}$ — o Fernando Arrabal - a quien Esslin incluye también en ese capítulo mencionado junto a otro dramaturgo español, Manuel de Pedrolo (Esslin, 1966: 199-206)_; o en el teatro de habla hispana, en general, como el dramaturgo cubano Virgilio Piñera, quien ganó en 1968 el premio Casa de las Américas de teatro por una obra que se enmarca en el teatro del absurdo: Dos viejos pánicos. Entre el jurado que le concedió dicho premio se encontraba Max Aub (Aub, 2002: 157, 173). Él mismo reconoció la «afluencia, en el concurso, de obras más o menos escritas a la última moda (Ionesco, Genet, Beckett, etc.) », es decir, más o menos de estética del absurdo, por los autores que nombra, hecho que atribuye a «que como los espectadores pertenecen ya a nuevas clases, buscan un nuevo tipo de teatro (lo que sería defendible con toda clase de peros y explicaciones)» (Aub, 2002: 147).

No sería la única mención a esta estética que haría Aub. Encontramos referencias a ella en sus diarios (p. ej., Aub, 2003: 348), donde incluso relata cómo intenta explicar a una joven, en relación con su pieza de juventud Una botella, que el suyo no es teatro del absurdo: «le hago ver que la botella existe, que en lonesco no existiría» (Aub, 2003: 463). Asimismo, entre los materiales destinados a conformar el marco históricoestético de su inconcluso Luis Buñuel, novela ${ }^{12}$, se encuentra un breve ensayo en el que Aub considera el teatro del absurdo como lo que podría parecer «una nueva manera» de interpretar el teatro y expone su opinión acerca de sus dos nombres principales:

El teatro, en el siglo XX, sigue un camino distinto, en la vanguardia, a las demás artes. [...] No hay en él un renovar como pudo significarlo el cubismo en la pintura o la aparición de Schoenberg [sic] en la música. [...] Habrá que esperar a la década de los sesenta para que efectivamente nos parezca que llega a la escena una nueva manera de interpretarlo. El antiteatro de lonesco —cuyos principios podemos situar hacia 1950 - no hace sino ridiculizar el lenguaje y no la acción, ya que la palabra «absurdo» se refiere al diálogo y no al movimiento de los personajes. Que no se trataba de una auténtica revolución lo probó el propio lonesco cuando se propuso hacer obras más considerables. El otro innovador 
de la época, Beckett, expresó el absurdo casándolo con la desesperación a la que no era ajena el temor a la bomba atómica. La desesperación de estos autores refleja una crisis, tan profunda como la que pudo sentir el mundo occidental ante la invasión árabe [...]. Pero, en el fondo, [...] no varió la esencia misma del teatro (ADV. C.17-1).

Volviendo a la pieza que nos ocupa, si nos fijamos en las réplicas de los personajes "corpóreos» de La familia Coconeta, detectamos que cada uno tiene asociado un leitmotiv, una obsesión sobre la que vuelve una y otra vez. La de Papá Coconet es, como se ha señalado, el cine: no deja de urdir posibilidades para una trama cinematográfica criminal, como indica el uso de la disolvencia. En el caso de Mamá Coconeta, tenemos, por una parte, la queja sobre las hijas que cogen sus cosas -las ligas, la bata, las zapatillas-; la preocupación hacia la familia cuando se sientan a la mesa -que coman unas, que tome las pastillas el otro, que vigile con el aparador la pequeña-; y, por otro lado, las preguntas sobre a qué estrella de Hollywood besó Henry Fonda. Mimín alude en sus intervenciones al estudio y a la universidad -estudió Literatura y Filosofía en la UNAM (Falkner, 2014) - , hecho que hace que pensemos en ella como una joven; en Elena como en una adolescente coqueta que repite sin cesar nombres masculinos, relacionados seguramente, como se verá, con amigos y conocidos; y Carmen, la pequeña "Coconetita», que es quien más papel tiene en la pieza, muestra un carácter mucho más infantil, contando sus cromos - que tal vez sean de banderas y países del mundo ${ }^{13}-$, chinchando a Elena con los chicos que le gustan, viendo cuántos chicles puede comprar con el dinero que tiene, o encargándose de las preguntas indiscretas como el color de los calzoncillos de Paquito Bosch. De manera muy somera, pues, Aub dibuja unos rasgos básicos para cada miembro de la familia. A pesar de la evidente falta de comunicación entre ellos, sí hay una interacción durante unas réplicas, en el momento en que se ponen a comer y las hijas se quejan de qué parte del muerto no quieren para cenar y su padre las manda «a comer y a callar».

Otros elementos de la micropieza se nos escapan. ¿Qué clase de simbolismo encierra chupar una paloma salida de un cadáver? ¿Serán las naranjas que anuncia la voz exterior una reminiscencia de Valencia, abandonada por las mujeres de la familia Aub poco tiempo atrás? ¿Cuál es la función de los espectros en la escena? ¿Esos espectros son vistos por la familia, o solo el de Paquito Bosch se hace visible y por ello mueren Mimín y Elena, del susto? ¿O simplemente nada de todo esto encierra ningún significado oculto, ya que Aub afirma que odia el simbolismo y le parece «un truco indecoroso que no trae nada» (Kemp, 1977: 16)? Resulta curiosa también la referencia al beso homosexual que menciona Mamá Coconeta - «¿Por qué besa Robert Taylor a Henry Fonda?»-, por las escasísimas referencias a esta orientación sexual que aparecen en la obra dramática de Aub, que encontramos, entre las piezas publicadas, solamente en Nuevo tercer acto (1947). Y, a pesar de que Aub recurrirá a jugar con el plano onírico en obras como Los muertos, Tránsito, Uno de tantos, Otros muertos o El hombre del balcón ${ }^{14}$, nada tiene que ver con la atmósfera onírica sugerida por el autor en esta pieza tan singular dentro de la producción aubiana. 
Ya Esslin, en el primer estudio sobre el «teatro del absurdo» referido, apuntaba que

el Teatro del Absurdo no es, por su misma naturaleza, una escuela o movimiento literario, ya que su esencia radica precisamente en la investigación libre y aislada que realiza cada escritor según su perspectiva individual. Sin embargo [...], las obras del Teatro del Absurdo han sabido dar cuenta del estrecho lazo que une a sus autores con las preocupaciones de nuestro tiempo y, al mismo tiempo, su deseo de conseguir una teatralidad nueva (Esslin, 1966: 185).

Ambas ideas - la clara tendencia personal y libre de este teatro; y el conseguir una teatralidad nueva y ocuparse, a la vez, de las preocupaciones de su tiempo- no podrían ser más afines, en el caso de la primera, a la libertad que desprende esta pieza, y, de la segunda, a la concepción teatral de la producción aubiana en su conjunto. Y, no obstante, como ya se ha apuntado, La familia Coconeta, en sus formas, encaja perfectamente con la estética del teatro del absurdo, pero no parece que lo haga en cuanto a su fondo, es decir, no queda nada claro qué tipo de crítica quiere expresar Aub con esta pieza, porque, de hecho, ni siquiera parece que haya una crítica detrás, como sí la suele haber en este teatro. Por lo que todo parece indicar que se trata de una pieza puramente lúdica.

Puestos a imaginar, tal vez Aub escribió esta pieza como una suerte de ejercicio dramatúrgico casero, para representar con su familia, o para la compañía de teatro no profesional El Tinglado, creada en $1948^{15}$ en su departamento de Euclides, 5, según recuerda Federico Álvarez (2011: 50), formada por

estudiantes del Vives y de la Academia ${ }^{16}[\ldots .$. . Desde los tiempos en que dirigía el teatro universitario El Búho de Valencia, Max Aub no dejó jamás de pensar en volver al escenario, en estrenar sus obras. Se encontró, de repente, con un grupo de amigas y amigos de sus hijas - Manolo Durán se acordará, porque él, su hermano Odón y su hermana Rosa María estaban allí todos los fines de semana y también mi hermana [Tere] y mi hermano [Eugenio], y los hermanos De Buen, Antonio Rizo (Passy), y Manolo Bonilla, y Pin Crespo y los hermanos Ugarte, Beatriz y Eduardo, y otros que no recuerdo [...]. El escenógrafo o decorador era siempre Carlos Marichal, hermano de Juan.

Y es que, según relata Carmen Aub, en la compañía «las estrellas éramos las hijas, sobre todo la mayor» (Meyer, 2001: 7). Con este «grupo teatral de la Federación Universitaria Escolar de españoles en México» representaron, entre otras, obras de Aub como La vuelta (referida a la de 1947) y Los guerrilleros; Ligazón, de Valle-Inclán, protagonizada por su hija Mimín y por Federico Álvarez (Meyer, 2001: 7 y Álvarez, 2011: 50); Los pobres y La risa del pueblo, de Carlos Arniches; Dúo, de Paulino Masip y La media naranja, de los hermanos Álvarez Quintero, según una breve reseña anónima aparecida en el Boletín de Información de la Unión de Intelectuales Españoles («Teatro», 1957: 25), además de «no sé cuántos entremeses» (Álvarez, 2011: 50).

El testimonio de Federico Álvarez acerca de El Tinglado aporta algo sustancial para que pensemos en esta obra como un ejercicio lúdico para la compañía. Si sostenemos que los personajes parten de personas reales de la cotidianidad aubiana, podríamos identificar parte de los nombres que Elena Coconeta/Aub recita como, por ejemplo, «Fede» -Federico 
Álvarez-, «Carlos»-Marichal-, «Paco»-Rojo, que, aunque no se le mencione como parte del grupo, era asiduo también a Euclides, 5 en aquella época ${ }^{17}$, o el de «Max» con el propio Aub. Podríamos también apellidar el "cadáver de Pin» como Crespo, que tendría relación con los espectros de los hermanos Rubén y Gustavo (Rojo), ya que Pin Crespo (1921-1978) fue también actriz en la época de oro del cine mexicano y, en su caso, exiliada republicana. Su mayor reconocimiento lo obtuvo con su trabajo en las tablas, donde protagonizó varias de las obras que Aub reseñaría en sus críticas como, por ejemplo, Corona de sombras, de Rodolfo Usigli (1947), o los entremeses cervantinos El viejo celoso y $\mathrm{La}$ guarda cuidadosa, dirigido el primero por Rivas Cherif, que ese mismo año se estrenaron en el Teatro Bellas Artes en una función organizada por la Unión de Intelectuales Españoles ${ }^{18}$ - a la que pertenecía Aub- y sobre la que el autor escribió, respecto a la actriz catalano-mexicana: «Pin Crespo, bonita como un sol, [...] y un tanto nerviosa con tanto teatro por delante, pero justa en su indignación que - a veces - le trababa tantito la lengua» (Aub, 2007: 224). Crespo debutó en el cine con Contra la ley de Dios (1946), película dirigida por Adolfo Fernández Bustamante, y en la que Aub trabajó como adaptador. Coincidieron también en Barrio de pasiones (1948), del mismo director y donde, como se ha indicado antes, Crespo compartió reparto con Gustavo Rojo.

Volviendo a la pieza que nos ocupa y a los personajes en clave, queda por identificar el espectro de Paquito Bosch, ya que el único exiliado que conozcamos que podría cuadrar con ese nombre es Francisco Bosch Morata (1901-1950), político, maestro y médico valenciano, de la generación de Aub, y que, al llegar a México, se estableció en el norte del país, en Mexicali. Otro Bosch, perteneciente este a la segunda generación del exilio republicano, sería el historiador Carlos Bosch (1919-1994), hijo del prehistoriador Pere Bosch i Gimpera (1891-1974), pero no concuerda con el nombre del espectro. Tal vez se trate, simplemente, de uno de los miles de exiliados anónimos que se establecieron en México con sus familias.

\subsection{Fecha de composición}

Al tratar de fechar la obra, se puede apreciar también el carácter innovador de esta escritura, que valoramos, como primera aproximación, que tuvo lugar entre 1947 y 1953, años en los que el teatro del absurdo, sobre todo en Europa, en Francia, florecía. Esta aproximación está basada en, por un lado, el hecho de que es una pieza que juega claramente con una cotidianidad familiar que no pudo darse hasta el reencuentro de Aub con su mujer e hijas y el inicio de su vida en común en México a partir de finales de 1946. Por otro, las cuestiones cinematográficas que son el motivo del personaje de Papá Coconet nos hacen suponer que Aub todavía estaba en la industria del cine, que abandonó en 1953. Esos dos motivos principales enmarcan la posible fecha de composición.

Pero hay más detalles que nos permiten saber que no se trata de una pieza posterior, como las referencias infantiles de Carmen Coconetita, incluso en el nombre del personaje, o las alusiones a la universidad de Mimín. Si la 
situamos en el extremo, 1953, nos encontraríamos con que Carmen tendría ya dieciséis años, demasiados para encajar con el carácter que se le atribuye en la micropieza; o que Mimín se encontraba ya casada y con su primera hija, Elaine Falkner Aub, nacida el 20 de agosto de ese año (Aub, 1998: 227), y que además se marchó de México el 7 de noviembre de 1951 (Aub, 2003: 101) para ir a vivir a Inglaterra con su marido, Neil Falkner.

Aunque si hay un dato que nos parece determinante para inclinarnos por fechar la composición de esta pieza en 1947 es su ubicación original manuscrita. El documento ADV. C.8-1 está conformado por una libreta que Aub bautiza en su primera página con el título de «Breve escala teatral para medir mejor nuestro mundo con leyes, reglas y textos de toda calaña, al alcance de los más variados caletres, y para mayor diversión de todos y cada uno». Y añade, para completar el diseño, «Escrita por Max Aub. En México y en el año de 1947» (ADV. C.8-1, p. [0]). Aub presenta esta portada como si se tratara de una cubierta con un trabajo de diseño gráfico que él reproduce a mano, variando las tipografías y los cuerpos, así como la disposición en la página. Este recopilatorio incluye: $A$ veces parece que estamos muertos (una primera versión de Los muertos), Entremés de El Director, A la deriva, La familia Coconeta, La certeza (obra inédita), Incertidumbre (primer título para Tránsito), Uno de tantos, [Nuevo] Tercer acto, La despedida (obra inédita), El olvido (titulado después Un olvido) y Cuando el mundo eche a andar de nuevo (título primitivo de La vuelta: 1947). La mayoría de estas obras - a excepción de La familia Coconeta, La certeza y La despedida ${ }^{19}$ _ fueron publicadas por el autor en la sección «Breve escala teatral para comprender mejor nuestro mundo» ${ }^{20}$ de su primera y segunda entrega de Sala de Espera ${ }^{21}$, en 1949 y 1950 , cosa que nos permite también confirmar con mayor seguridad la fecha de escritura de este texto.

\section{El armario de Elena (ca. 1950)}

\subsection{Descripción de los materiales textuales}

En cuanto a El armario de Elena, desconocemos la procedencia del manuscrito cuya reproducción facsimilar se incluye en Cartas a mi hija Elena (Aub, 2013). No se ha encontrado rastro de esta pieza en ninguno de los archivos consultados para este trabajo, por lo que deducimos que forma parte de la colección personal que atesoran sus herederas: primero su hija Elena Aub Barjau, fallecida en mayo de 2020, quien facilitó este manuscrito al editor del libro-estuche; y ahora su nieta Teresa Álvarez $\mathrm{Aub}^{22}$.

El manuscrito reproducido es visiblemente breve, ya que ocupa poco más de un folio. Parece estar escrito en tinta azul, sin ninguna corrección y sin marcas de haber sido pasado a máquina. El título aparece subrayado y centrado, así como aparece centrado también el «Telón» final. El resto del texto no contiene ninguna singularidad en su escritura. Se aprecian abreviaturas en las didascalias de personaje, recurso típico para escribir con mayor fluidez las primeras versiones de las piezas, porque permite centrarse en el diálogo y no en cuestiones formales; el nombre de Elena 
aparece subrayado en su última intervención; y las acotaciones no se presentan entre paréntesis.

Todo ello indica que la obra fue redactada del tirón y sin mucha (o ninguna) revisión posterior, como se deduce también de algunos errores ortotipográficos fácilmente enmendables (tildes o signos de puntuación ausentes, por ejemplo), cosa que explicaría igualmente la ausencia de otras versiones en los fondos archivísticos del autor. Por lo que podríamos considerar este manuscrito como la versión definitiva del texto.

\subsection{Contenido y análisis de la pieza}

Esta micropieza, más breve incluso que La familia Coconeta, está estrechamente relacionada con ella en tanto que tiene como protagonista a Elena Aub, y el autor, es decir, su padre, la caracteriza del mismo modo que en la anterior: como una joven coqueta que ahora no solo pronuncia los nombres masculinos, sino que colecciona a los hombres en su armario, como veremos. La acción tiene lugar en «un cuarto, con un gran armario. Elena está sentada, cosiendo». Su primera intervención es: «Enrique González Martínez es un gran poeta. Enrique Gonzáles Martínez acaba de cumplir cincuenta años de ser poeta. Enrique González Martínez ha escrito muchos libros buenos. El primer libro de Enrique González Martínez se llama Gabriel López».

Efectivamente, el tan citado Enrique González Martínez (1871-1952) fue un eminente poeta mexicano modernista, de fama internacional ${ }^{23}$. Su carrera diplomática le llevó a establecerse en España entre 1924 y 1931, años en los que trabó amistad con gran parte de la intelectualidad española y europea. Al igual que otros críticos exiliados como Enrique Díez-Canedo ${ }^{24}$, Aub, a lo largo de los años, dedicó —además de un obituario- varios artículos a la vida y a la obra del poeta, entre ellos «Enrique González Martínez y su tiempo", aparecido en Cuadernos Americanos en 1952; o «Enrique González Martínez. Vida y poesía», en la Revista de la Universidad de México en 1971, reproducido luego en sus Ensayos mexicanos (Aub, 1974b: 169-190); además de incluirle, y en primer lugar, en su antología de la poesía mexicana de 1950 a $1960^{25}$ (Aub, 1960: 2339). En el último artículo arriba mencionado, Aub se muestra contundente al valorarle: «dejemos sentado, en primer término, que Enrique González Martínez es el poeta más importante de su generación mexicana» (Aub, 2007: 867), y lo equipara con Antonio Machado. Incluso alude a él, igual que aludía a don Antonio, como «maestro»: «se van muriendo los maestros que uno más quería y nos vamos quedando al filo de la muerte. Allí está Machado, aquí Canedo y este otro don Enrique» (Aub, 2007: 875).

También da noticia de su muerte - a los ochenta años, el 19 de febrero de 1952- y hasta de su entierro, al que asistió, en sus diarios: «Muerte de Enrique González Martínez. Tan lleno, que no hay por donde cogerlo. Completo. Fue un hombre completo» (Aub, 1998: 203); «Habló Vasconcelos ante la tierra abierta que iba a recibir el cuerpo de González Martínez. Y es hermoso. Porque ambos defendieron los opuestos 
conceptos del mundo. $Y$ no dejaron de estimarse, sintiendo cada uno que el otro disintiera totalmente de su luz» (Aub, 2003: 105-106).

Por tanto, no es baladí que el poeta al que alaba Elena hasta en diez ocasiones en la pieza, como veremos, sea Enrique González Martínez. Como nos informa Aub a través de las palabras de la hija, el modernista «acaba de cumplir cincuenta años de ser poeta». Este detalle nos permite fechar la obra alrededor de 1950, ya que, aunque el primer poemario publicado por González Martínez, Preludios, apareció en 1903, publicó versos en periódicos y revistas desde 1885. De modo que, en algún punto entre las dos cifras, pero no en los extremos (demasiado temprana 1935; demasiado tardía 1953, ya que el poeta murió un año antes, como hemos señalado, y aparecerá al final de la pieza), y desde luego a partir de finales de 1946, por los motivos arriba referidos acerca de la reagrupación de la familia Aub Barjau, nuestro autor escribió esta micropieza para su hija Elena, según afirmó el editor del libro-estuche en la presentación del mismo, que tuvo lugar en Madrid el 18 de noviembre de 2013.

Tras esa primera intervención de la mediana de los Aub, y al mencionar a «Gabriel López» —que, obviamente, no es el título ni del primero ni de ninguno de los libros de González Martínez-, la acotación nos indica que «entra Gabriel López. Elena lo mira y baja la vista», en una señal clara de rubor o timidez, y mantienen el siguiente diálogo 26 :

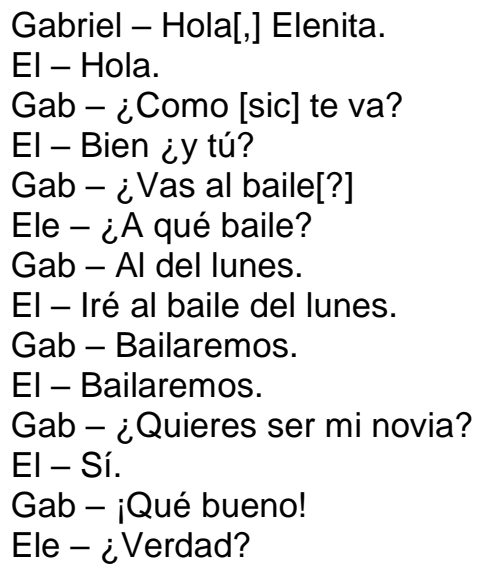

Tras este diálogo, «Elena coge a Gabriel y lo cuelga en el armario». La identidad de este Gabriel López podría corresponderse con la del escritor mexicano Gabriel López Chiñas (1911-1983), director de Radio Universidad (UNAM) - cargo que desempeñaría Aub más de una década después ${ }^{27}$ en los años de escritura de la pieza ${ }^{28}$. Sin embargo, parece más probable que se trate de un joven cualquiera, de edad más pareja a la de la protagonista de la micropieza. Y, si nos fijamos en que Elena lo presenta como el título del primer poemario de González Martínez, Preludios, podríamos considerar la entrada del personaje y el diálogo posterior un preludio del objetivo dramático de la protagonista.

A partir de aquí, la escena se repetirá en bucle, pero con distintos nombres, es decir, con distintos muchachos que Elena irá colgando en su gran armario, cual colección de pretendientes: 
Elena ${ }^{29}$, cosiendo [-] Enrique González Martínez es un gran poeta, Enrique González etc.

La escena se repite diez veces, cambiando los nombres de los personajes que entran [y] serán por orden: Gabriel, Paco, Max, Federico, Néstor, Luis, Eugenio, Federico, Jorge, Eugenio, Federico y Antonio. Al final entra Enrique González Martínez y encierra a Elena en el armario. Se oye un gran ruido, el armario desaparece y sale Elena gritando:

- ¡Felipe! ¡Felipe!

Atraviesa la escena corriendo y baja el

Telón.

Esta acotación final encierra todo el desarrollo de la pieza tras el diálogo inicial que, al parecer, se repetirá con cada uno de los muchachos que irá entrando $-\mathrm{y}$ esta estructura de repeticiones con ligeras variantes es también característica del teatro del absurdo-, hasta la aparición del poeta modernista quien, en un gesto de lo que podría ser enojo por haberse oído nombrar tanto por Elena, la encierra también en el armario con el resto de sus pretendientes. Aub parece reservar para González Martínez la peripecia final, si es que podemos llegar a considerarla así, que contempla también una suerte de castigo para la coqueta muchacha, a juzgar por su reacción al salir gritando y corriendo.

Igualmente, el nombre que gritará Elena, «Felipe», no se corresponde con ninguno de los chicos que ha ido guardando en su armario. Como en la pieza anterior, el listado de nombres debía corresponderse con los de los jóvenes que más o menos cortejaban a Elena Aub en aquel momento. Parece que el autor escribe nombres de más, porque la escena «se repite diez veces» pero, en cambio, el listado incluye doce variantes, con lo que, incluso descartando el nombre de Gabriel, seguiría sobrando uno. El de Federico, por ejemplo, se repite tres veces; el de Eugenio, dos. Tal vez Aub, en un descuido, los escribiera pensando en la misma persona, justamente por la falta de revisión que parece denotar el manuscrito, como ya se ha apuntado.

Esto nos indica también el carácter de divertimento, de poca importancia, que tenía para el propio dramaturgo. Podemos considerarla, pues, un mero ejercicio lúdico, una broma teatral para su hija mediana, porque incluso muestra menos entidad que La familia Coconeta.

\section{Conclusiones}

Tras la descripción y el análisis detallado de ambas micropiezas, podemos confirmar, en cierto modo, su intrascendencia en un sentido literario, si las consideramos en relación con el resto de la producción teatral del autor. Destacan como una suerte de aplicación formal, que no de fondo - ya que contienen rasgos característicos de esta estética teatral, a pesar de no compartir con ella el afán de crítica o de respuesta al vacío existencial, como se ha señalado-, del teatro del absurdo, en boga en esos años, y que no conocíamos hasta el momento en la trayectoria aubiana. A pesar del interés de esta poética teatral híbrida que propone Aub, ambas piezas carecen de la profundidad dramatúrgica que el autor imprimía a la mayoría de sus obras. Aun así, entre ambas hay claras diferencias, porque La familia Coconeta está, sin duda, más trabajada y pensada que El armario 
de Elena, tanto a nivel literario, como teatral, como en los estadios del proceso de escritura.

Eso se aprecia también en los materiales textuales, cuya observación arroja luz a dicho proceso y, por ende, al tiempo y la atención empleados por Aub en su elaboración. Es particularmente significativo el único manuscrito conocido de El armario de Elena, reproducido facsimilarmente en Cartas a mi hija Elena: de ser, efectivamente, el único material textual de esta pieza, como parece indicar su ausencia en los archivos internacionales consultados, es un ejemplo perfecto de primer borrador que nunca pasa a una revisión o reescritura y que se convierte, por tanto, en versión final.

A pesar de la poca importancia dramática de estas obras en el conjunto de la producción aubiana, sí resultan de gran interés si las leemos como piezas en clave, especialmente La familia Coconeta. Si bien podemos encontrar al trasunto de nuestro autor o trazas autobiográficas, más o menos sutiles, en algunas de sus obras escénicas —como El rapto de Europa, Tránsito, La vuelta: 1964 o más claramente en Paso del señor Director General de Seguridad y Monólogo con Federico y con Miguel, por ejemplo-, es muy poco común que Aub proponga piezas protagonizadas por su entorno familiar y cotidiano. $Y$, al hacerlo, ofrece un retrato de su familia y de su ambiente en esos primeros años de exilio mexicano y de reagrupación familiar.

Porque, además, ambas obras nos hablan no solo del dramaturgo, sino también del hombre. Tanto La familia Coconeta como El armario de Elena son ejemplos de cómo Aub desbordaba teatro en todos los ámbitos de su vida, desde en su producción profesional literaria hasta en los juegos y las complicidades familiares con sus hijas. Según el testimonio de Elena Aub, «eran obras que nos regalaba para representar los domingos» (ap. Manrique Sabogal, 2013), afirmación que concuerda con esa imagen que compartía Álvarez (2011: 50) de una casa llena de muchachas y muchachos que componían el círculo de amistades de sus hijas y que acudían a Euclides, 5 los fines de semana para «jugar» al teatro.

Finalmente, merece la pena señalar la transculturalidad latente que encierran ambas micropiezas en tanto reflejo de la vida y las relaciones en el exilio. En La familia Coconeta se muestra la convivencia, por un lado, de los distintos intereses de la familia, desde los estudios hasta el trabajo en el gremio cinematográfico —principal ocupación de muchos escritores exiliados republicanos durante los primeros años-, pasando por el entretenimiento infantil; $y$, por otro, si nos remitimos a los personajes en clave, la convivencia de distintas generaciones de exiliados, no solamente republicanos, como sería el caso de los hermanos Rojo. En cuanto a El armario de Elena, a pesar de su brevedad, es innegable el peso del gran poeta modernista mexicano, Enrique González Martínez, en la pieza. De ahí que una joven exiliada republicana de segunda generación conozca y elogie su obra, en tanto puente entre la tradición poética hispánica e hispanoamericana. Este valor y el aprecio literario que sentía Aub por el poeta mexicano quedan reflejados también en otros textos del autor, como se ha visto. 
Por todo ello, La familia Coconeta y El armario de Elena suponen dos rarezas en el conjunto de la producción teatral de Aub. Han pasado desapercibidas por la crítica, en primer lugar, por no haberse publicado en vida del autor y encontrarse inéditas hasta 2013; luego, por haber sido incluidas en una edición de difícil acceso; y, finalmente, por considerarlas obras de poca enjundia dramática, ejercicios lúdicos para el divertimento de sus hijas y sus amistades. De hecho, si el propio Aub no las publicó ni las incluyó, por ejemplo, en su Sala de Espera, debió ser también porque ni él las consideraba obras que debieran sobrevivirle.

Sin embargo, hoy nos permiten conocer otra faceta del dramaturgo empedernido que fue, una nueva estética en su teatro siempre innovador, un objetivo distinto en su afán por la escritura, y otros matices humanos, personales, que configuran también su condición de padre y su visión de su propia familia, que no solemos encontrar en sus obras más conocidas.

\section{Bibliografía citada}

ÁLVAREZ, F. (2011): «Setenta años: muerte y vida del exilio» en Aznar Soler, M. y López García, J. R. (eds.), El exilio republicano de 1939 y la segunda generación, Sevilla: Renacimiento, 41-51.

ANTEQUERA BERRAL, E. (2014): Buñuel: novela, de Max Aub. Un testimonio generacional y un reto literario. Los materiales preparatorios para la obra. Tesis doctoral, Valencia: Universitat de València.

ARMAS MARCELO, J. J. (2009): Mercedes Pinto, una sombra familiar, Canarias: Tauro.

AUB, M. (1949): Sala de Espera, 1-10, México D. F.: Gráficos Guanajuato.

AUB, M. (1950): Sala de Espera, 11-20, México D. F.: Gráficos Guanajuato.

AUB, M. (1951): Sala de Espera, 21-30, México D. F.: Impresora Juan Pablos.

AUB, M. (1960): Poesía mexicana (1950-1960), México D. F.: Aguilar.

AUB, M. (1974a): Manual de historia de la literatura española, Madrid: Akal.

AUB, M. (1974b): Ensayos mexicanos, México D. F.: Universidad Nacional Autónoma de México.

AUB, M. (1986): [Cartas a Rafael Prats Rivelles] en Prats Rivelles, R., «Mi correspondencia con Max Aub», Batlia, 5, 129-131.

AUB, M. (1998): Diarios (1939-1972), Barcelona: Alba.

AUB, M. (2002): Enero en Cuba, Segorbe: Fundación Max Aub.

AUB, M. (2003): Nuevos diarios inéditos (1939-1972). Sevilla: Renacimiento.

AUB, M. (2007): Los tiempos mexicanos de Max Aub. Legado periodístico (19431972), Madrid - Segorbe: Fondo de Cultura Económica - Fundación Max Aub.

AUB, M. (2010): Juego de cartas, Granada: Cuadernos del Vigía.

AUB, M. (2013): Cartas a mi hija Elena, Madrid: Centro de Arte Moderno.

AUB, M. (2021): La gallina ciega, Sevilla: Renacimiento.

AZNAR SOLER, M. (1998): «Los diarios de Max Aub» en Aub, M., Diarios (19391972), Barcelona: Alba.

AZNAR SOLER, M. (2003): Los laberintos del exilio. Diecisiete estudios sobre la obra literaria de Max Aub, Sevilla: Renacimiento.

AZNAR SOLER, M. (2008): «La Unión de Intelectuales Españoles en México (1947-1956)» en Boletín de Información de la Unión de Intelectuales Españoles en México, agosto de 1956 - mayo de 1961, Sevilla: Renacimiento, XXIII-LXXVI.

BLECUA, A. (2012): Estudios de crítica textual, Madrid: Gredos.

DIAGO, N. (2015): «Max Aub: estrenos americanos», Episkenion, 3/4, 177-186. 
DÍAZ BETHENCOURT, J. (1995): «Pituka de Foronda, un viaje sin retorno» en De Dalí a Hitchcock. Los caminos del cine: actas del V Congreso de la Asociación Española de Historiadores del Cine, A Coruña: Centro Galego de Artes da Imaxe, 351-357.

Diccionario de la Real Academia Española. Versión electrónica 23.5. $<$ https://dle.rae.es> [08/12/2021].

DÍEZ-CANEDO, A. (2005): «Traducir poesía. Correspondencia entre Enrique Díez-Canedo y Enrique González Martínez», Literatura mexicana, XVI-2, 187-205. ESSLIN, M. (1966): El teatro del absurdo, Barcelona: Seix Barral.

FALKNER, M. (2014): «A Mimín Falkner Aub», El Correo de Euclides, 9, 9-10.

GARCÍA DE FEZ, S. (2011): «México y España en los discursos identitarios de los colegios del exilio en la Ciudad de México (1939-1950)» en Aznar Soler, M. y López García, J. R. (eds.), El exilio republicano de 1939 y la segunda generación, Sevilla: Renacimiento, 267-274.

GÓMEZ VÁZQUEZ, J. (2017): «La microtextualidad en el teatro breve actual: del teatro breve al microteatro español y su reverso con la microficción hispánica», EPOS, 23, 115-138.

HERAS GONZÁLEZ, J. P. (2014): «Actores, directores y compañías del exilio republicano en México» en Heras, J. P. y Paulino Ayuso, J. (eds.), El exilio teatral republicano de 1939 en México, Sevilla: Renacimiento, 51-83.

KEMP, L. A. (1972): The Plays of Max Aub: A Kaleidoscopic Approach to Theater. Tesis doctoral, Madison: University of Madison.

KEMP, L. A. (1977): «Diálogos con Max Aub», Estreno, III-2, 8-11 y 15-19.

KING COBOS, J. (2007): Memorias de Radio UNAM, México D. F.: Universidad Nacional Autónoma de México.

LÁZARO, E. (2018): «Revistas unipersonales. Sala de Espera» en Glondys, O. (ed.), La prensa cultural de los exiliados republicanos. I: Los años cuarenta, Sevilla: Renacimiento, 206-213.

LÁZARO, E. (2019): «Paso del señor Director General de Seguridad: el homenaje teatral a Max Aub en su visita a España en 1969» en Feuillastre, A. L. y Ruiz Cano, M. (eds.), El teatro de protesta. Estrategias y estéticas contestatarias en España (1960-1980), Paris: L'Harmattan, 81-92.

LÁZARO, E. (2021): «Piezas microteatrales inéditas de Max Aub», Anales de la Literatura Española Contemporánea, 46-2, 49-78.

LÁZARO SANZ, E. (2019): «Nací para escribir teatro». Presentación y estudio de la obra dramática inédita de Max Aub. Tesis doctoral, Bellaterra: Universitat Autònoma de Barcelona.

LLARENA, A. (2003): Yo soy la novela. Vida y obra de Mercedes Pinto, Las Palmas de Gran Canaria: Cabildo de Gran Canaria - Instituto Canario de la Mujer. LLUCH-PRATS, J. (2009): «Editar a los clásicos contemporáneos: aspectos de la última voluntad de un autor» en Álvarez Barrientos, J.; Cornago Bernal, Ó.; Madroñal Durán, A. y Menéndez-Onrubia, C. (coords.), En buena compañía. Estudios en honor de Luciano García Lorenzo. Madrid: Consejo Superior de Investigaciones Científicas, 1181-1192.

LLUCH-PRATS, J. (2010): «Los estudios de génesis textual» en Arcocha-Scarcia, A.; Lluch-Prats, J. y Olaziregui Alustiza, M. J. (eds.), En el taller del escritor. Génesis textual y edición de textos. Vizcaya: Universidad del País Vasco, 19-54. MALGAT, G. (2013): Max Aub et la France ou L'espoir trahi, Marseille: L'atinoir. MANRIQUE SABOGAL, W. (2013): «El Max Aub más íntimo», El País, 18 de noviembre,

<https://elpais.com/cultura/2013/11/18/actualidad/1384797932_960486.html> [27/10/2021].

MEYER, E. (2001): «Entrevista a María Luisa y Carmen Aub», Sala de Espera, 2, 5-7.

MONTI, S. (2002): «Estudio introductorio» en Aub, M., Teatro breve (Obras completas, vol. VII-B), Valencia: Institució Alfons el Magnànim, 7-62. 
MORALEDA, P. (1989): Temas y técnicas del teatro menor de Max Aub, Córdoba: Universidad de Córdoba.

NAVARRETE MAYA, L. (1993): «González Martínez, Enrique» en Ocampo, A. M. (dir.), Diccionario de escritores mexicanos, siglo $X X$, vol. III, México D. F.: Universidad Nacional Autónoma de México, 267-277.

OLMEDO, I. (2016): «Pinto Armas, Mercedes» en Aznar Soler. M. y López García, J. R. (eds.), Diccionario biobibliográfico de los escritores, editoriales y revistas del exilio republicano de 1939, vol. IV, Sevilla: Renacimiento, 43-45.

ORTIZ FLORES, P. (1997): «López Chiñas, Gabriel» en Ocampo, A. M. (dir.), Diccionario de escritores mexicanos, siglo XX, vol. IV, México D. F.: Universidad Nacional Autónoma de México, 423-424.

PAULINO AYUSO, J. (2010): «Historia y crítica del estreno de La vida conyugal, de Max Aub», Acotaciones, 25, 47-69.

PÉREZ MÍGUEZ, C. (2013): «Nota de editor» en Aub, M., Cartas a mi hija Elena. Madrid: Centro de Arte Moderno, $s / n$.

PRATS RIVELLES, R. (1986): «Mi correspondencia con Max Aub», Batlia, 5, 128131.

Retorno a Max Aub, Madrid: Instituto Cervantes, 2017.

SÁNCHEZ ZAPATERO, J. (2016): Max Aub: Epistolario español, Kassel: Reichenberger.

SIRERA, J. L. (2002): «Estudio introductorio» en Aub, M., Primer teatro (Obras completas, vol. VII-A), Valencia: Institució Alfons el Magnànim, 15-49.

SOLDEVILA, I. (2006): «Estudio introductorio» en Aub, M., Los muertos, Segorbe: Fundación Max Aub, 9-42.

«Teatro», Boletín de Información de la Unión de Intelectuales Españoles, 5 (1957), 23-25.

VALCÁRCEL, C. (2018): «Dulce epistolario. Cartas a mi hija Elena de Max Aub», El Correo de Euclides, 13, 236-252.

VALDIVIA, P. (2014): José Ricardo Morales de mar a mar. Teatro transnacional, exilio y periferia, Sevilla: Renacimiento.

VALENDER, J. (2007): "Max Aub y su antología de Poesía mexicana (19501960)» en Valender, J. y Rojo, G. (eds.), Homenaje a Max Aub, México D. F.: El Colegio de México, 253-280.

XIRAU, R. (1991): «Enrique González Martínez» en Goic, C. (coord.), Historia y crítica de la literatura hispanoamericana. II: Del romanticismo al modernismo, Barcelona: Crítica, 483-486.

YOUSFI LÓPEZ, Y. (2014): “La recepción de El embustero en su enredo en Sudamérica: 1944-1946», Laberintos, 16, 299-309.

\footnotetext{
1 Estas dos últimas piezas estarían en el límite del género microteatral y su inclusión o no dependería, de hecho, del montaje y su tiempo de escenificación.

2 Para un análisis del teatro de circunstancias de Aub, cf. Sirera, 2002: 30-41.

${ }^{3}$ Las fotografías, dedicatorias y, especialmente, los materiales epistolares (cartas y postales) han sido presentados y estudiados en Valcárcel (2018).

${ }^{4}$ Cuando nos referimos a versión definitiva o texto definitivo en cuanto a los manuscritos y mecanuscritos presentados, nos estamos refiriendo a lo que la crítica genética prefiere llamar versión última o texto último (cf. Lluch-Prats, 2010: 34).

${ }^{5}$ La carta que se conserva en el Archivo de la Fundación Max Aub (en adelante, AFMA) tiene algunas ligeras omisiones respecto a la versión citada y reproducida en Prats Rivelles (1986). Estas variantes se deben, seguramente, a que las cartas custodiadas en el AFMA escritas por Aub son, por lo general, copia de las originales que mandaba y no contienen «las adiciones que muchas veces de forma manuscrita incluía» (Sánchez Zapatero, 2016: 2), como se comprueba en los casos en los que el destinatario ha conservado la original maxaubiana.

${ }^{6}$ Se trata de otra pieza breve que no suele contabilizarse entre el teatro del autor, por haberla incluido en su diario La gallina ciega (1971). En ella, Aub recrea las peripecias de la organización de la lectura de fragmentos de sus obras que llevó a cabo él mismo en el
} 
Teatro Fígaro de Madrid el 24 de octubre de 1969, y que estuvo marcada por el encontronazo con la censura (cf. Lázaro, 2019).

${ }^{7}$ Marcamos en cursiva las acotaciones para facilitar su lectura y distinguirlas del resto del texto y de otras didascalias, a pesar de que no aparezcan así ni en el mecanuscrito de La familia Coconeta ni en el manuscrito de El armario de Elena.

8 Para una mayor información sobre la vida y la obra de esta autora, cf. Llarena, 2003; o, para una aproximación más general a ella, cf. Armas Marcelo, 2009 y Olmedo, 2016.

${ }^{9}$ En esta última pregunta, cuando aparece sin acentuar, por lo que, si no se trata de una errata, Mamá Coconeta pregunta si llueve cuando hace sol, y, en caso de que se trate de una tilde olvidada, estaría preguntando en qué momento se dan cada uno de los dos fenómenos climatológicos. En el mecanuscrito apreciamos varias palabras a las que les falta la tilde, por lo que ambas posibilidades de significado podrían ser correctas.

${ }_{10}$ Los subrayados, que se corresponden con las didascalias de personaje, son del original.

11 Para más información acerca de la dramaturgia de José Ricardo Morales, cf. Valdivia, 2014 y concretamente, en cuanto a este estreno y la relación entre Morales y la Xirgu, las pp. 83-85. Igualmente, sobre la recepción del montaje en los distintos países latinoamericanos donde lo giró la actriz, cf. Yousfi López, 2014.

12 Para un estudio de los materiales destinados a la biografía inconclusa de su amigo y cineasta, cf. Antequera Berral, 2014.

${ }_{13}$ De hecho, esta Carmen de La familia Coconeta no es el único personaje maxaubiano con fijación por los cromos y sellos. En Juego de cartas (1964), también uno de los remitentes (Emmanuel) acusa de ello a su destinatario (Doroteo), imitando un tono muy parecido al que emplea la hija pequeña en la micropieza: «Esa manía de los sellos y ahora de los cromos: -Mamá, me hace falta el $601 \ldots$ Si no lo tengo me meo. El diez centavos carmesí de Honduras y el diez centavos encarnado de Mónaco...» (Aub, 2010: s/p, carta 6 de tréboles/espadas).

${ }^{14}$ Para un análisis de Los muertos, cf. Soldevila, 2006; para Tránsito, cf. Aznar Soler, 2003: 283-295; para Uno de tantos y Otros muertos, cf. Moraleda, 1989; y para El hombre del balcón, cf. Monti, 2002: 58-62.

${ }^{15}$ Algunos antiguos integrantes de la compañía sitúan su creación en 1942 y desvinculada de Aub (Heras González, 2014: 57).

${ }_{16}$ Se refiere al Instituto Luis Vives y a la Academia Hispano Mexicana, fundadas en 1939. Junto con el Colegio Madrid, fundado en 1941, fueron las tres instituciones de enseñanza promovidas por el exilio español en México para la educación de la segunda generación (y sucesivas, ya que tanto el Vives como el Madrid siguen en activo). Hubo una cuarta, el Colegio Hispano-Mexicano Ruiz de Alarcón, que solo estuvo en funcionamiento de 1939 a 1943 (García de Fez, 2011: 267).

17 Esta información fue proporcionada por su hermano, el artista Vicente Rojo, quien no podría tratarse del «Vicente» mencionado en la pieza, ya que su relación con Aub tuvo un inicio más tardío, hacia finales de los años cincuenta. Pero sí recuerda cómo una década antes los progenitores Aub estaban «rodeados de jóvenes que iban tras las bellas hermanas Mimí[n] y Elena [...], que querían llegar a ser de "La familia Coconeta"».

${ }^{18}$ Para más información sobre esta representación y el homenaje en el que se enmarcó, cf. Aznar Soler, 2008: LXIII-LXV.

19 Para un análisis de estas dos piezas inéditas de Aub, cf. Lázaro Sanz, 2019: 368-375 y 410-418, respectivamente.

${ }^{20}$ Aub varió ligeramente el título de la sección teatral de su revista en cada una de sus tres entregas. En la primera apareció tal y como lo hemos citado (Aub, 1949: s/n); en la segunda, cambió mundo por tiempo (Aub, 1950: s/n); y en la tercera, además de mantener el cambio de la última palabra, sustituyó comprender por medir (Aub, 1951: s/n).

${ }^{21}$ Para más información sobre esta revista, cf. Aznar Soler, 2003: 81-92 y Lázaro, 2018.

22 Es el caso también de otros documentos pertenecientes a la colección personal de la familia que, en los últimos años, han podido verse, por ejemplo, en la exposición producida por el Instituto Cervantes - bajo la dirección de Juan Manuel Bonet y comisariada por Juan Marqués - y que fueron reproducidos en el catálogo de la misma (Retorno..., 2017).

${ }^{23}$ Para más información sobre Enrique González Martínez y su obra, cf. Navarrete Maya, 1993 y Xirau, 1991.

${ }^{24}$ La amistad y la admiración que se tenían Díez-Canedo y González Martínez queda reflejada no solo en los artículos que se dedicaron respectivamente el uno al otro, sino también en su correspondencia, que da cuenta del inicio de su relación en 1909, y que ha sido estudiada y reproducida por la historiadora (y nieta del poeta y crítico español) Aurora Díez-Canedo (2005). 
${ }^{25}$ Para un estudio de ese libro, su recepción y la posición que tomará Aub como antólogo, cf. Valender, 2007.

${ }^{26}$ A pesar de que las reproducciones manuscritas cuentan con una transcripción en el estuche-libro, la transcripción que ofrecemos la hemos realizado directamente del manuscrito facsímil, para una mayor exactitud.

27 Acerca de la labor de Aub en Radio UNAM, cf. King Cobos, 2007: 56-76.

${ }_{28}$ Para más información sobre Gabriel López Chiñas y su obra, cf. Ortiz Flores, 1997.

${ }^{29}$ El subrayado es del original. 